\title{
Multifunctional Oil Absorption with Macroporous Polystyrene Fibers Incorporating Silver-Doped ZnO
}

\author{
Ali A. El-Samak, Deepalekshmi Ponnamma, Mohammad K. Hassan,* Samer Adham, Alamgir Karim,* \\ Ali Ammar, Maha Alser, Samar Shurbaji, Nahla O. Eltai, and Mariam Al Ali Al-Maadeed
}

Cite This: ACS Omega 2021, 6, 8081-8093

Read Online

ACCESS | Lلll Metrics \& More | 回 Article Recommendations | S1 Supporting Information

ABSTRACT: Hydrophobic microporous polystyrene (PS) fibers are fabricated by a solvent-induced phase-separation-assisted electrospinning method. Zinc oxide $(\mathrm{ZnO})$ and silver-doped zinc oxide $(\mathrm{Ag}-\mathrm{ZnO})$ nanomaterials with variable morphologies are added to the PS fibers, to investigate the influence of multifunctional nanofiller addition on the porosity and consequent oiladsorbing properties for different oil types. The doping of silver as well as the uniformity in particle distribution are confirmed by scanning electron microscopy and the energy-dispersive spectral analyses. The porosity of the fibers and their crystallinity effect depend on the hydrophobicity and surface properties of these microporous nanofilled fibers. $\mathrm{Ag}-\mathrm{ZnO}$, specifically in $2 \mathrm{wt}$ $\%$, enhanced the pore size and distribution in PS porous fibers, thereby enhancing the oil-adsorbing property and its hydrophobicity. In-depth analysis of the oil adsorption mechanism is done for the fibers, both qualitatively and


quantitatively, to demonstrate its correlation with the structural integrity of the fibers. The PS/2Ag- $\mathrm{ZnO}$ composite also exhibits the highest antibacterial performance against Staphylococcus aureus, a general indication of antibiological fouling properties of these oilseparating films. The antifouling/antibacterial activity of the nanoparticles and high oil sorption capacity of the highly porous PS composites show great potential for use in water-treatment-related applications.

\section{INTRODUCTION}

Selective wetting behavior, clean water production, reusability, low cost of production, and simplicity in design are the essential criteria of membranes used for general water purification, ${ }^{1-3}$ and more specifically oil-water separation. ${ }^{4-7}$ In addition, high membrane porosity is also desirable as porous structure affects the permeation rate of oil/water emulsion through the membranes. ${ }^{6}$ Conjugated microporous superhydrophobic polymer-coated sponge, reported by Li et al., ${ }^{8}$ can separate oils and nonpolar organic solvents in addition to toxic or polar organic solvents from water. Such porous materials like sponges have large pore volumes, good mechanical stability in harsh environments, flexibility, and low cost, but the possibility of simultaneous oil and water absorption limits their wider applicability. Zhang et al. demonstrated ${ }^{9}$ selective oil adsorption by silicone nanofilaments coated on superhydrophobic polyester fibers; however, the mechanical stability was significantly low. Subsequently, low-cost and durable superhydrophobic polyester materials of high mechanical and chemical stabilities were fabricated by dip-coating the fibers in a nanocomposite solution of tetraethoxysilane and $n$ hexadecyltriethoxysilane. ${ }^{10}$ Such spongy structures quickly absorbed petrol, diesel, and crude oil very selectively from water and maintained superhydrophobicity even after 90 days of immersion in oils, harsh mechanical damages, and 10 absorption-desorption cycles. Chen et al. reported ultralight magnetic foams based on polyurethane sponge template ${ }^{11}$ consisting of three-dimensional (3D) interconnected microtubes of $40-50 \mu \mathrm{m}$ and $190-300 \mathrm{~nm}$ thicknesses and demonstrated its fast and selective oil removal from water under a magnetic field. In fact, the structural features of the foams were dependent on the tunable composition and conformation of the polyelectrolyte precursors and the concentration of the embedded magnetic particles. The sorption capacity of a particular material varies depending on the nature and type of oil, morphology of the material, and porosity. ${ }^{12-16}$ While the butyl rubber-based macroporous gel reported up to $38 \mathrm{~g} / \mathrm{g}$ sorption capacity, with reusability for 20 cycles, ${ }^{14}$ polypropylene porous disks possessed only up to 16 $\mathrm{g} / \mathrm{g}$ capacity. ${ }^{13}$ However, the general material used in commercial oil cleanup processes is the walnut shell granular media filter with comparatively lower sorption capacity of up to $0.74 \mathrm{~g} / \mathrm{g} .{ }^{15}$ Cotton fiber, on the other hand, reported $30-40$

Received: November 22, 2020

Accepted: February 23, 2021

Published: March 17, 2021

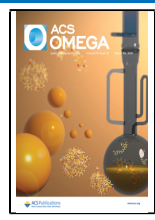


$\mathrm{g} / \mathrm{g}$ sorption capacity, only with durability up to three cycles. ${ }^{16}$ The aforementioned materials tend to adsorb oil through trapping the oil droplets within their voids through capillary forces, especially porous fibrous sorbents, which are capable of retaining the oil droplets within its porous structure as well, therefore having an increased capacity in comparison to nonporous fibrous sorbents.

Electrospinning has emerged as the most convenient method to fabricate and tune nanofibers of suitable thickness, aspect ratio, and porosity. Highly porous nonwoven fiber mats of flexible and lightweight design are reported based on the electrospinning method. ${ }^{17,18}$ The nanoscale pore size, highly interconnected pore structures, and the capability to design active chemical properties at the nanoscale are the significant features of this manufacturing process. ${ }^{19}$ This causes highefficiency oil separation at a low energy cost. Zhai et al. reported a nanofibrous membrane of fluorine-containing triptycene-based polyimide, fabricated by electrospinning for separating oil/water emulsions with high efficiency and flux. ${ }^{20}$ Electrospinning was also practiced by Zhao et $\mathrm{al}^{21}$ in fabricating hierarchically porous poly(L-lactide) fabrics and by Panatdasirisuk et al. ${ }^{22}$ in preparing polycaprolactone (PCL) fibers for oil/water separation. The wettability of the PCL membrane surface was improved by adding a nonionic surfactant and oleic acid prior to electrospinning so that the membrane was able to separate oil/water emulsion droplets as small as $18 \mathrm{~nm}$ in size. ${ }^{22}$ These evidences confirm the possible dependence of the pore size, shape, and 3D network nature of the electrospun fiber on the oil/water separation efficiency and flux.

Porous fibers and membranes are largely explored in recent times, as many flexible membranes useful for oil/water separation can be made out of them. ${ }^{23}$ Nanoparticles can further add unique functional activity to the porous materials by synergy of their high surface area as well as that offered by the porous structures. For instance, $\mathrm{ZnO}$ nanomaterials possess outstanding properties and the superhydrophobic biocomposite membrane fabricated from $\mathrm{ZnO}$-embedded cellulose acetate was reported with good optical, bactericidal, and water repellent properties, through which multifunctional membranes can be targeted. ${ }^{24}$ Singh et al. also demonstrated the efficiency of $\mathrm{ZnO}$ in designing polyacrylonitrile-based porous nanofibers of $60 \mathrm{~nm}$ diameter for photocatalytically degrading naphthalene and anthracene dyes. ${ }^{25}$ Moreover, the electrospun polyacrylonitrile fibers functionalized with silver$\mathrm{ZnO}$ heteronanostructures of 20-30 $\mathrm{nm}$ diameter reported comparatively higher antibacterial properties toward both Gram-negative Escherichia coli and Gram-positive Micrococcus luteus bacteria than their single counterparts. ${ }^{26}$ Since silver particles are involved, such types of materials can be a good choice for effective air/water filtration and water disinfection.

Superhydrophobic polystyrene (PS) is widely investigated for its possible porous structure and effective oil-water separation performance. ${ }^{27,28} \mathrm{Wu}$ et al. reported fibrous electrospun PS sorbents capable of absorbing diesel oil, motor oil, peanut oil, and silicon oil from a mixture of oil/ water emulsions. ${ }^{27}$ Depending on the fiber morphology and diameter, the adsorption capacities of different oils by PS film were $7.13,81.40,112.30$, and $131.63 \mathrm{~g} / \mathrm{g}$, respectively, for diesel oil, silicon oil, peanut oil, and motor oil. Cheng and Tung introduced a one-step electrospinning process for fabricating PS fibrous sorbents by combining non-solventinduced phase separation (NIPS) with the electrospinning technique. ${ }^{28}$ Chlorobenzene (CB) is a good solvent for the PS, whereas dimethyl sulfoxide (DMSO) is a nonsolvent. When a desirable ratio of these liquids is used to dissolve PS, the NIPS takes place while electrospinning. As the spinning vaporizes the solvent, pores are generated on the fibers. The pore size and fiber diameter were optimized by varying the solvent ratios and the final tailored sorbents had remarkable oil adsorption capacity and rate. Following the same method of one-step electrospinning, herein, we report the fabrication of PS nanocomposite porous fibers for their selective oil adsorption capabilities.

Very specifically, this work aims at synthesizing silver-doped $\mathrm{ZnO}$ particles and their influence on the porous PS fiber properties. The $\mathrm{Ag}^{+}$-ion doping is anticipated to produce decreased particle size and thus enhanced surface area in modified $\mathrm{ZnO}(\mathrm{Ag}-\mathrm{ZnO})$ particles. These doped nanomaterials, at the same time, can target multifunctional application such as biofouling resistance in the nanocomposite fibers. Moreover, the nanoparticles with modified morphology and structure can control the pore size and distribution on the PS polymer fibers. This can influence the oil-adsorbing capacity of the NIPS PS fibers with a higher oil-adsorbing mass percentage. The current porous fibers are strong enough to resist the antifouling issues that the conventional membranes possess. Moreover, the developed PS nanocomposite porous fibers offer thermal and mechanical stabilities compared to the currently employed oil/water separating polymer composites. The oil-adsorbing mechanism is also verified here by the morphology images and the total organic content values. In short, the present study and system is demonstrative of what may be feasible as part of a series of experimental procedures for oil/water separation, probably at the final stages

\section{EXPERIMENTAL TECHNIQUES}

2.1. Materials. Zinc acetate dihydrate, silver nitrate, oxalic acid, ethanol, CB, and DMSO were purchased from SigmaAldrich. Polystyrene (PS, $M_{\mathrm{w}} \sim 350000 \mathrm{~g} / \mathrm{mol}$ ) pellets were also commercially obtained from Sigma-Aldrich. All of the reagents and chemicals were used as such without any additional chemical treatments.

2.2. Synthesis of $\mathrm{ZnO}$ and Silver-Doped $\mathrm{ZnO}$. $\mathrm{ZnO}$ and silver-doped $\mathrm{ZnO}$ were synthesized following a nonaqueous colloidal precipitation method. For this, $50 \mathrm{mM}$ zinc acetate $(10.98 \mathrm{~g})$ was dissolved in $500 \mathrm{~mL}$ of ethanol at $60{ }^{\circ} \mathrm{C}$ with continuous stirring $(30 \mathrm{~min})$. To this solution, an ethanolic solution of oxalic acid (100 mM, $12.55 \mathrm{~g}$ in $200 \mathrm{~mL})$ was slowly added and magnetically stirred for $2 \mathrm{~h}$. The $\mathrm{ZnO}$ precipitated as colloidal semigel was dried overnight at $80{ }^{\circ} \mathrm{C}$ and later calcined for $2 \mathrm{~h}$ at $500{ }^{\circ} \mathrm{C}$. For silver-modified $\mathrm{ZnO}$, a separate ethanolic dissolution of silver nitrate at $3 \mathrm{~mol} \%$ was also added to the zinc acetate-oxalic acid mixture with constant stirring. The silver nitrate-to-zinc acetate ratio was maintained as 2 atom \% according to the previously published reports. ${ }^{29}$ This is due to the fact that the optimum $\mathrm{Ag} / \mathrm{Zn}$ ratio (1-2 atom \%) causes $\mathrm{Ag}^{+}$-ion substitution in the $\mathrm{ZnO}$ structure, without the formation of Ag clusters. ${ }^{30}$ The steps of drying and calcination were carried out under the same conditions for $\mathrm{ZnO}$ preparation, and both $\mathrm{ZnO}$ and $\mathrm{Ag}-\mathrm{ZnO}$ powders were characterized.

2.3. Fabrication of $\mathrm{PS} / \mathrm{ZnO}$ and $\mathrm{PS} / \mathrm{Ag}-\mathrm{ZnO}$ Nanocomposites. PS pellets were mixed with 30/70 (v/v) DMSO and $\mathrm{CB}$ solvent mixture with heat $\left(50{ }^{\circ} \mathrm{C}\right)$-assisted magnetic stirring $(12 \mathrm{~h})$. The homogeneous solution around $30 \mathrm{wt} \%$ 
obtained was electrospun using single capillary spinneret, and the fibers were collected on a rotating collector placed $15 \mathrm{~cm}$ away from the needle (22 gauge, Hamilton of $0.718 \mathrm{~mm}$ diameter) tip. The solution feed rate was fixed as $0.5 \mathrm{~mL} / \mathrm{h}$, and the voltage applied was around $10 \mathrm{kV}$. CB is a good solvent, and DMSO is a nonsolvent for the PS and during electrospinning; the solvent evaporates, while the nonsolvent induces phase separation. A high CB evaporation rate increases the fraction of DMSO with time, and the solution crosses the liquid-liquid demixing line and phase-separates. In addition, the solvent evaporation causes moisture condensation to form water, which can dissolve DMSO to lower the solvent quality and thus accelerate the phase separation. Depending on the volume fraction (with increasing DMSO), phase separation induces larger pores on the surface. Using the same conditions, PS nanocomposites of $\mathrm{ZnO}$ and $\mathrm{Ag}-\mathrm{ZnO}$ were also made by varying the concentration of nanomaterials. PS-1AgZnO, PS$2 \mathrm{AgZnO}$, and $\mathrm{PS}-3 \mathrm{AgZnO}$, respectively, represent the nanocomposites containing 1, 2, and 3 wt $\% \mathrm{Ag}-\mathrm{ZnO}$. For property comparison, PS- $\mathrm{ZnO}$ was also made by mixing PS with 2 wt \% $\mathrm{ZnO}$.

2.4. Characterization Techniques. Structural details of $\mathrm{ZnO}, \mathrm{Ag}-\mathrm{ZnO}$, and their PS nanocomposites were observed through X-ray diffraction (XRD, PANalytical Empyrean diffractometer), using $\mathrm{Cu} \mathrm{K} \alpha$ radiation of wavelength 1.54 $\mathrm{nm}$. The scattering angle was fixed from 10 to $90^{\circ}$ at a scan step size of $0.013^{\circ} / \mathrm{min}$. The input voltage and tube current were, respectively, $45 \mathrm{~V}$ and $40 \mathrm{~mA}$. Nicolet/FTIR 670 (Thermo Nicolet) was used to observe the Fourier transform infrared (FTIR) spectra of all samples. Energy-dispersive spectroscopy (together with scanning electron microscopy (SEM)) and X-ray photoelectron spectroscopy (XPS; AXIS Ultra DLD from Kratos Analytical) were used to study the elemental composition of samples. The morphologies of $\mathrm{ZnO}$, $\mathrm{Ag}-\mathrm{ZnO}$, and their PS nanocomposites were studied using a scanning electron microscope (Nova Nano SEM 450) with voltage variation from $200 \mathrm{~V}$ to $30 \mathrm{kV}$. The fiber samples were sputtered with a thin layer of gold before the SEM analysis. A TECNAI G2 transmission electron microscope (TEM), TF20 model, was used to confirm the desired shape, size, and lattice structure of the powdered nanomaterials. All samples were placed on a $3 \mathrm{~mm}$ copper grid, followed by the bombardment of electrons by argon ions accelerated at $200 \mathrm{kV}$. While the thermal stability of $10 \mathrm{mg}$ of the fiber samples was tested using a PerkinElmer TGA4000 thermogravimetric analyzer, in a temperature range of $30-800{ }^{\circ} \mathrm{C} @ 10{ }^{\circ} \mathrm{C} / \mathrm{min}$, the mechanical properties of the fibers (rectangular pieces of $2 \mathrm{~cm} \times 5 \mathrm{~cm}$ dimensions and $0.7 \mathrm{~mm}$ average thickness) were tested using Lloyd materials testing instrument by AMETEK. The sample was pulled at a constant rate of $2 \mathrm{~mm} / \mathrm{min}$, thus generating a strain vs stress graph that enables the derivation of the elongation, tensile strength, and Young's modulus. The degree of hydrophobicity was evaluated by determining the contact angle measurements according to the sessile drop method. The Young-Laplace model was used to determine the contact angle, which is directly correlated to the surface roughness of the prepared samples, using the OCA35 system and chargecoupled device (CCD) camera, which were required to capture the droplet accumulation on the sample surface. Up to $3 \mu \mathrm{L}$ of water was placed atop the fibers, followed by a $3 \mathrm{~s}$ grace period before the contact angle was calculated, to achieve thermodynamic equilibrium between the sample and the droplet. The tests were repeated five times at different locations on the sample to determine the mean contact angle value. The oil/water separation efficiency of the membrane was addressed through oil adsorption tests, oil/water separation laboratory-scale experiments, recyclability tests, and antibacterial studies (biofouling), as listed below.

2.4.1. Oil Adsorption Capacity Test. The oil adsorption capacity test was performed for all of the porous fibers using three types of oil: olive oil, engine oil, and mineral oil. The oils were selected according to the viscosity variations and their contamination to water streams and presence in different wastewater resources such as municipal and industrial wastewater. The densities of the mineral oil, olive oil, and engine oil were, respectively, 0.87, 0.92, and $0.91 \mathrm{~g} / \mathrm{mL}$. During the oil adsorption tests, $10 \mathrm{mg}$ of each porous spun fiber was fully immersed in different oils for $60 \mathrm{~min}^{28}$ then, they were taken out and allowed to drain under gravity, for another $60 \mathrm{~min}$. Following this, the oil-adsorbed fiber samples were dried at normal temperature, using a dryer (for $5 \mathrm{~min}$ ). The oil adsorption studies were done according to the reported procedure, $^{28}$ according to which the draining and drying process ensures no unadsorbed oil present on the sample surface. After complete oil draining, the fibers were weighed again to find the $\%$ increase $(\mathrm{g} / \mathrm{g})$ adsorption ability toward different oils. The increase in the fiber's weight was calculated using formula 1 , where $W_{2}$ is the final weight and $W_{1}$ is the initial weight of the samples, after and before the oil adsorption respectively. To compare the performance of the PS fibers, a similar piece of Whatman Grade 0858 filter paper of same weight was also tested for oil adsorption.

$$
\% \text { increase }(\mathrm{g} / \mathrm{g})=\frac{\left(W_{2}-W_{1}\right)}{W_{1}}
$$

2.4.2. Oil/Water Separation Test. An oil/water emulsion was made at $200 \mathrm{ppm}$ oil concentration using ultrasonication for $2 \mathrm{~h}$, and this mixture was used to check the efficiency of oil/water separation by the sample. The laboratory setup for oil-water separation consists of a Buchner flask, a Buchner funnel, and a metal membrane holder along with a vacuum pump. The fiber sheet was cut into a small circular piece of 2 $\mathrm{cm}$ diameter and a thickness of $15 \mathrm{~mm}$, then placed on the metal holder and first conditioned with distilled water using an external pump allowing $5 \mathrm{~mL} / \mathrm{s}$ flow rate of the solution. The oil/water mixture (about $200 \mathrm{~mL}$ ) was further poured through the fibers at a $5 \mathrm{~mL} / \mathrm{s}$ flow rate, and clean water was collected from the flask, leaving the oil-adsorbed fibers above.

2.4.3. Fiber Cleaning and Recyclability Test. The oiladsorbed fibers were submerged in a $0.1 \mathrm{M} \mathrm{NaOH}$ solution for about $10 \mathrm{~min}$ and further washed with distilled water. This is followed by overnight heating to ensure the removal of water residue, before proceeding to the next cycle of oil adsorption. The cleaning solution was adopted from commercial vendors such as Lennetech, which recommend the usage of basic solutions in the cleaning of ultrafiltration (UF) membranes (alkali neutralization). After $\mathrm{NaOH}$ washing and drying, the fibers were tested again for oil/water separation efficiency. The treated filtrate starting from Section 2.4.2 was subsequently used as the initial filtrate for the next cycle; this process was repeated for five subsequent cycles, and the oil removal efficiency was tested through SEM images and total organic content (TOC) data.

2.4.4. Fiber Biofouling Testing. The antibacterial properties of the fibers were tested using the common bacteria 

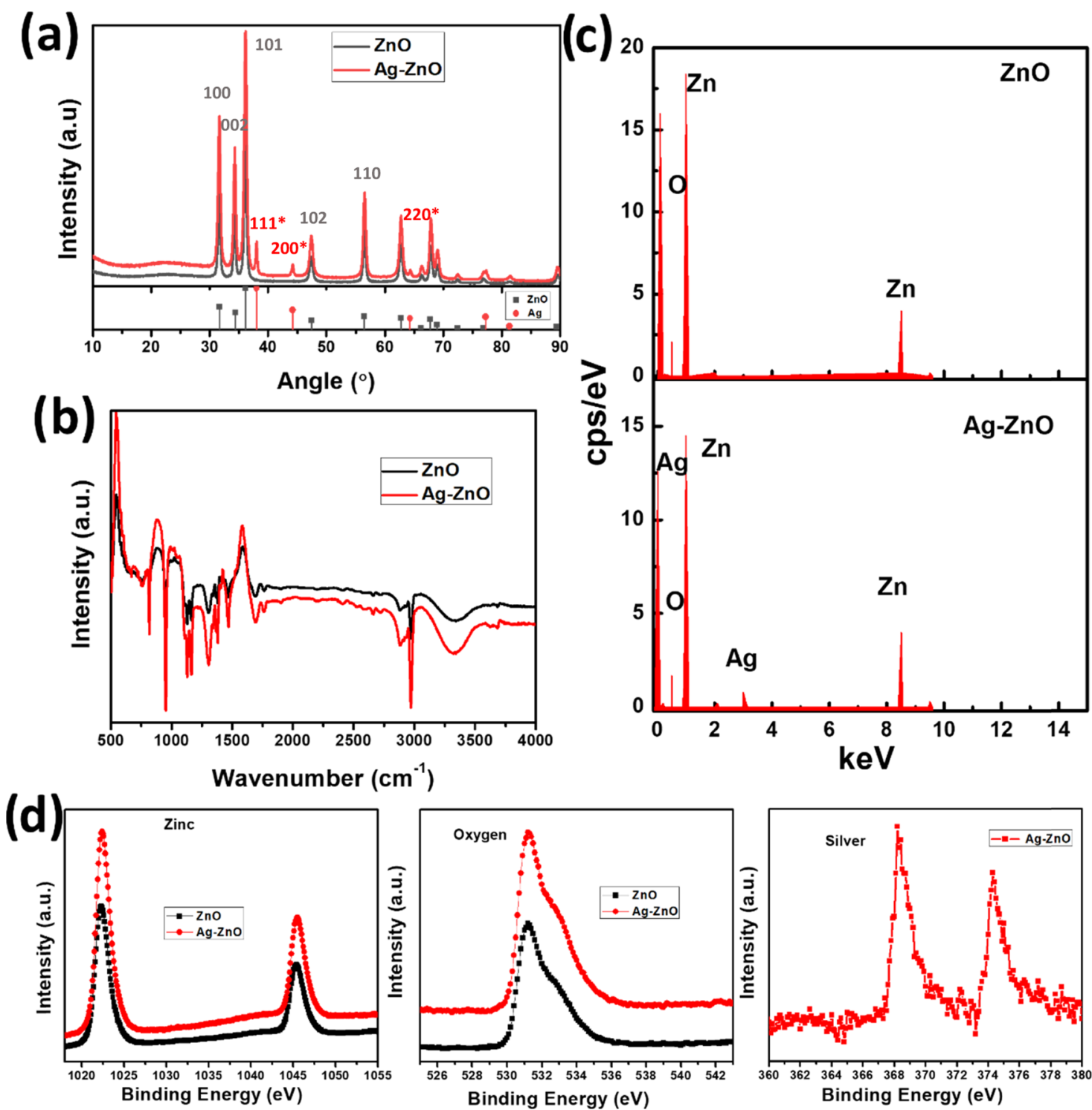

Figure 1. Structural analysis of $\mathrm{ZnO}$ and $\mathrm{Ag}-\mathrm{ZnO}$ : (a) XRD patterns, (b) FTIR spectra, (c) EDAX patterns, and (d) XPS spectra.

Staphylococcus aureus. The bacteria were lab-grown according to the research of Sabri et al. ${ }^{31}$ followed by incubation of the membrane samples within the bacterial solution for $24 \mathrm{~h}$ at 37 ${ }^{\circ} \mathrm{C}$. A single colony was suspended in phosphate-buffered saline (PBS), and the membrane samples were soaked along with the negative control and plated on agar media for $24 \mathrm{~h}$ at $37{ }^{\circ} \mathrm{C}$. The growth of $S$. aureus was qualitatively assessed by scanning electron microscopy (SEM). The membranes were fixed by $4 \%$ paraformaldehyde to preserve their morphology. As the quantification of $S$. aureus was not possible by SEM, a different approach was followed using fluorescent staining and manual quantification of bacterial cells. Here, bacterial cells were collected from the material's surface by sonicating the material membranes and the controls in equal volumes of PBS for $7 \mathrm{~min}$. The suspension was centrifuged at $5000 \mathrm{rpm}$ for 5 $\min$. The cells were then diluted five times and stained with 4 $\mu \mathrm{g} / \mathrm{mL}$ 4,6-diamidino-2-phenylindole (DAPI). DAPI is a specific stain for DNA in cells, which offers better detection and certainty. Therefore, the stained bacterial suspension was counted using a hemocytometer by injecting $10 \mu \mathrm{L}$ of the sample inside the hemocytometer groove. The cells in the middle hemocytometer squares were counted at $60 \times$ magnification using an Olympus fluorescent microscopy to obtain the average number of cells, and the following formula was used to find the total cell count. Regular cellulose sheets that are usually used for bacteria counting were used in this experiment as control.

$$
\begin{aligned}
& \text { total cell count }(\text { cells } / \mathrm{mL}) \\
& =\text { average number of cells } \times \text { dilution factor } \times 10^{4} \\
& \quad \text { (hemocytometer constant) }
\end{aligned}
$$

\section{RESULTS AND DISCUSSION}

3.1. Structural and Morphological Analysis of $\mathrm{ZnO}$ and Ag-Doped $\mathrm{ZnO}$. Both unmodified and modified $\mathrm{ZnO}$ nanomaterials were characterized to investigate the effectiveness of Ag doping and its influence on the $\mathrm{ZnO}$ structural and morphological features. Figure 1 illustrates the structural characteristics of both $\mathrm{ZnO}$ and $\mathrm{Ag}-\mathrm{ZnO}$ as evidenced from the XRD, FTIR, energy-dispersive X-ray analysis (EDAX), and XPS studies. The XRD patterns in Figure la show a typical 


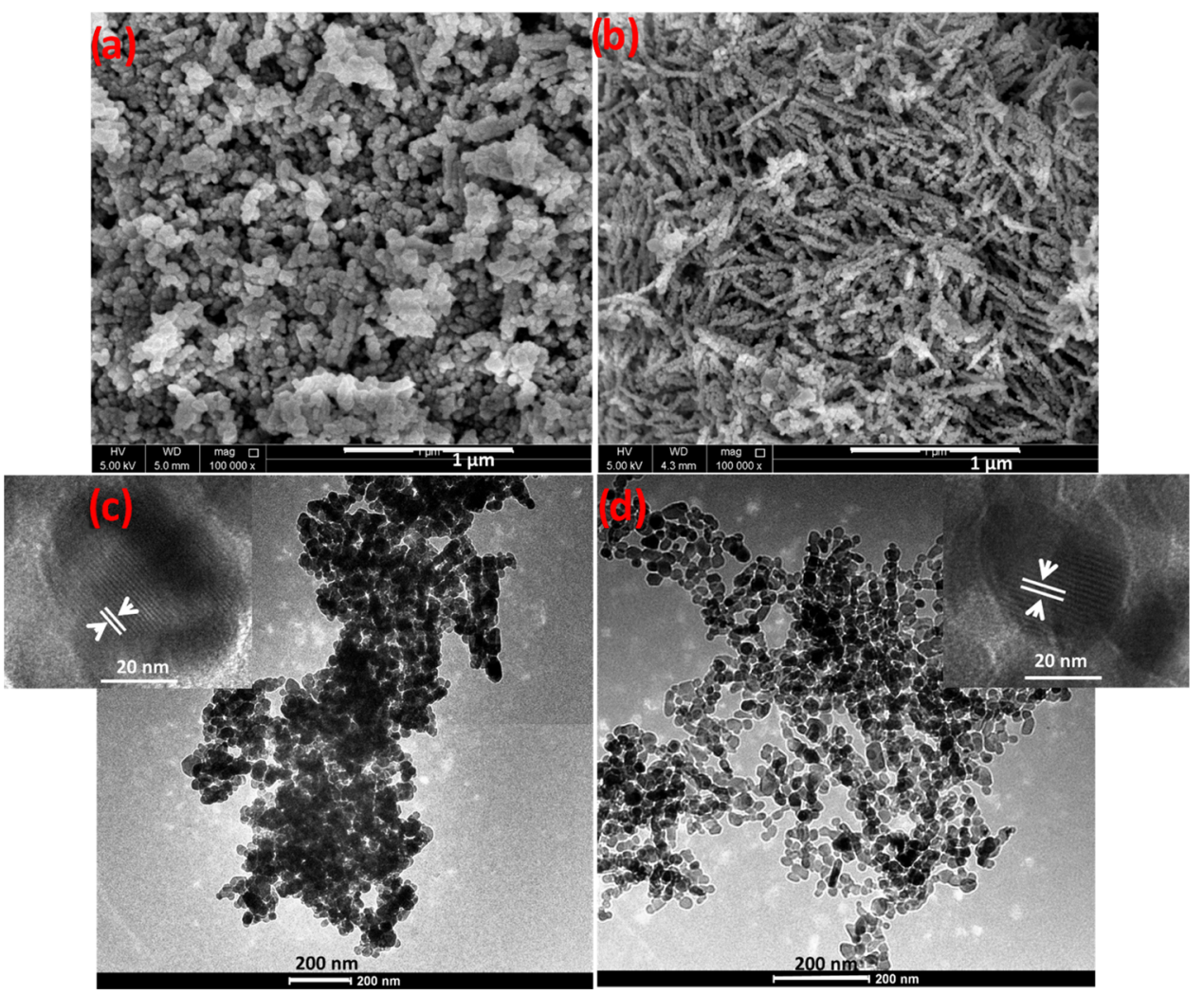

Figure 2. SEM images of (a) $\mathrm{ZnO}$ and (b) Ag- $\mathrm{ZnO}$; TEM images of (c) $\mathrm{ZnO}$ and (d) Ag-ZnO.

wurtzite structure for the $\mathrm{ZnO}$ according to JCPDS, 36-1451 as the high-intensity peaks ranging from 30 to $37^{\circ}$ belong to the (100), (002), and (101) planes. ${ }^{32-37}$ The characteristic patterns for the $\mathrm{ZnO}$ and $\mathrm{Ag}^{+}$ions from the literature are given in the same figure as basis. Additional peaks observed at 38.1, 44.5 , and $64.5^{\circ}$, corresponding to the (111), (200), and (220) plane structures for the $\mathrm{Ag}-\mathrm{ZnO}$, suggest the presence of $\mathrm{Ag}$ in face-centered cubic ( $\mathrm{fcc}$ ) phase; however, the low intensity of the peaks illustrates the lower possibilities of cluster formation. ${ }^{33}$ During silver doping, either the $\mathrm{Ag}^{+}$ions can be substituted for $\mathrm{Zn}^{2+}$ in the $\mathrm{ZnO}$ lattice or it can be presented as an interstitial atom. This is in accordance with the observation made by Pillai and co-workers, ${ }^{32}$ where silver addition to $\mathrm{ZnO}$ caused reduction in crystallite size. More specifically, the silver addition expands the $\mathrm{ZnO}$ lattice due to the substitution of larger $\mathrm{Ag}^{+}$ions with the $\mathrm{Zn}^{2+}$ ions in the lattice. The interstitial occupancy of $\mathrm{Ag}^{+}$ions causes charge differences between both $\mathrm{Ag}^{+}$and $\mathrm{Zn}^{2+}$ ions, which generates more oxygen vacancies. This reduces the average crystallite size of the Ag-doped $\mathrm{ZnO}$ particles, verified according to the Rietveld refinement. ${ }^{29}$

FTIR spectra in the range of $500-4000 \mathrm{~cm}^{-1}$ show a similar kind of bond vibrations for both $\mathrm{ZnO}$ and $\mathrm{Ag}-\mathrm{ZnO}$ samples. Peaks near 500, 3000, and $3300 \mathrm{~cm}^{-1}$ correspond to $\mathrm{Zn}-\mathrm{O}$ stretching, $-\mathrm{OH}$ bonding, and asymmetric $\mathrm{C}-\mathrm{H}$ stretching vibrations. ${ }^{33}$ The absorption bands near $1000-500 \mathrm{~cm}^{-1}$ and at $1380 \mathrm{~cm}^{-1}$ can be attributed to the different vibrational influence of the $-\mathrm{CO}_{3}{ }^{2-}$ group. ${ }^{32}$ When comparing the two spectra for both $\mathrm{ZnO}$ and $\mathrm{Ag}-\mathrm{ZnO}$, small shifts in peak positions are observed; this can be due to the partial $\mathrm{Ag}^{+}$ substitution in the $\mathrm{ZnO}$ lattice. Moreover, no other prominent peaks are present in both samples, indicating the phase purity. Energy-dispersive spectroscopy (EDS) studies illustrate the phase composition and purity of the nanomaterials as represented in Figure 1c. The well-defined peaks observed for the $\mathrm{Zn}, \mathrm{O}$, and $\mathrm{Ag}$ ions in the Ag-modified $\mathrm{ZnO}$ suggest efficient ionic doping. ${ }^{34}$ As expected, no silver peak was observed in the $\mathrm{ZnO}$ sample. Structural analysis was again done using the XPS spectra, and the results obtained are shown in Figure 1d. For pure $\mathrm{ZnO}$ and $\mathrm{Ag}-\mathrm{ZnO}$, symmetrical peaks at 1044.8 and $1021.7 \mathrm{eV}$ are observed, respectively, due to the $\mathrm{Zn}\left(2 \mathrm{p}_{1 / 2}\right)$ and $\mathrm{Zn}\left(2 \mathrm{p}_{3 / 2}\right)$ orbit coupling. The split peaks with a binding energy difference of $23 \mathrm{eV}$ indicate the powerful spin-orbit coupling process. The variation in binding energies from the stoichiometric values of 1045.1 and 1022.1 $\mathrm{eV}$ is because of the charge transfer variations from $\mathrm{Zn}^{2+}$ to $\mathrm{O}^{2-}$ caused by the vacancies. With silver doping, the binding energies remain the same corresponding to the wurtzite structure of $\mathrm{Ag}-\mathrm{ZnO} .^{35}$ In the oxygen spectrum, the asymmetric curve indicates two different types of atoms, i.e., the $\mathrm{O}^{2-}$ ions of $\mathrm{Zn}-\mathrm{O}$ bond and the one in the hydroxyl group. For $\mathrm{Ag}-\mathrm{ZnO}$, elemental mapping was done for the silver, and the results show two peaks at 368.3 and $374.3 \mathrm{eV}$ attributed to $\mathrm{Ag}\left(3 \mathrm{~d}_{3 / 2}\right)$ and $\mathrm{Ag}\left(3 \mathrm{~d}_{5 / 2}\right)$, respectively. The binding energy difference of $6 \mathrm{eV}$ shows the presence of metallic silver in the Ag- $\mathrm{ZnO}$ sample. Since the electronegativity of $\mathrm{Ag}$ is higher than that of $\mathrm{Zn}$, electrons are transferred from $\mathrm{Zn}$ to $\mathrm{Ag}$, and this causes control of the defects in the $\mathrm{ZnO}$ lattice. ${ }^{33}$

The morphology of the nanomaterials was further addressed by SEM and TEM studies, as represented in Figure 2. It is clear from the figure that silver doping causes no change in the shape of the particles but changes the size and dimension of ZnO. Both SEM and TEM clearly illustrate the decrease in dimension of the particles. More clearly, the average particle size of $\sim 50 \mathrm{~nm}$ for the $\mathrm{ZnO}$ was reduced to $\sim 30 \mathrm{~nm}$ in the case of $\mathrm{Ag}-\mathrm{ZnO}$. The change in the $\mathrm{ZnO}$ particle size with $\mathrm{Ag}$ 


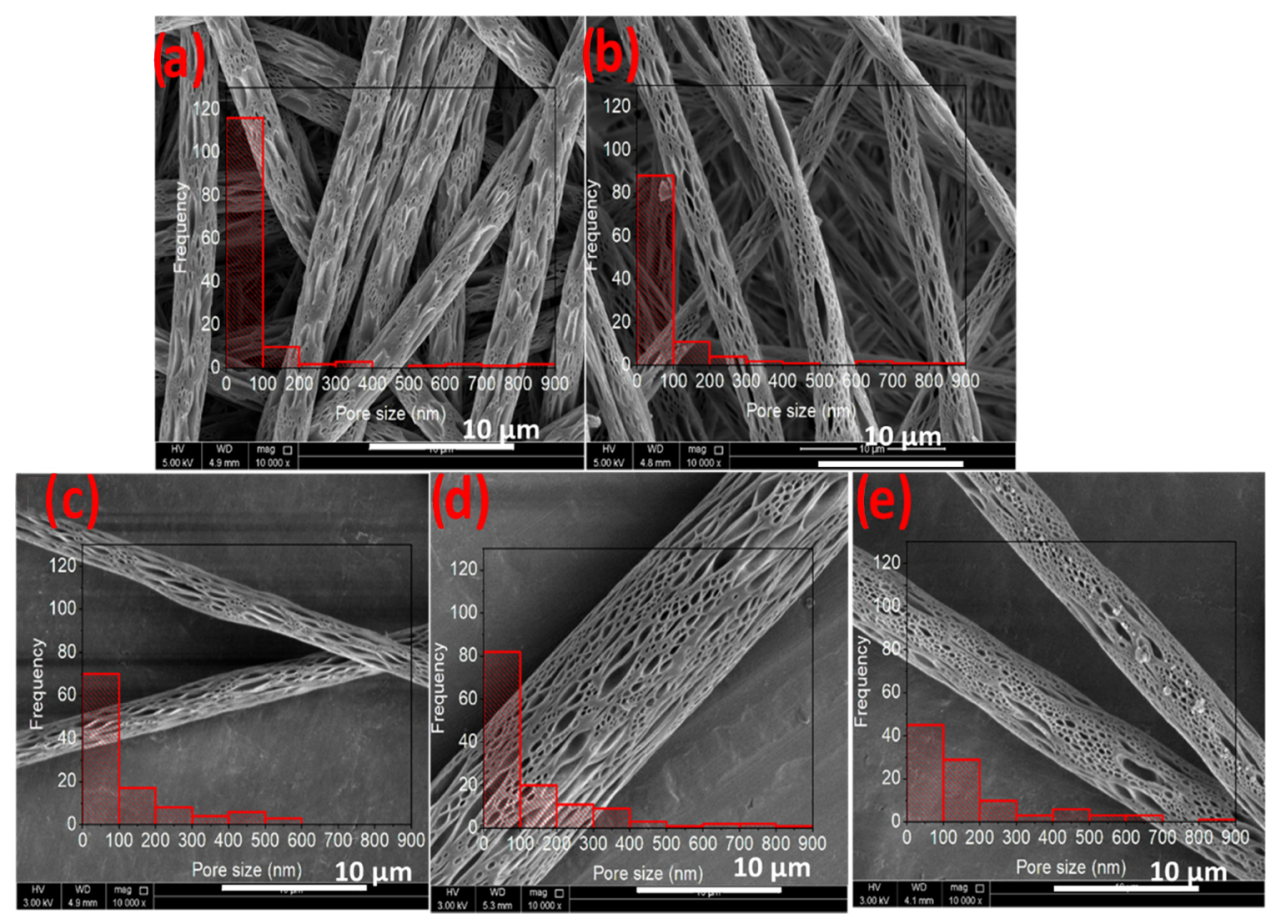

Figure 3. SEM images for the (a) PS and PS nanocomposites with (b) 2 wt \% $\mathrm{ZnO}$, (c) 1 wt \% Ag- $\mathrm{ZnO}$, (d) 2 wt \% Ag- $\mathrm{ZnO}$, and (e) 3 wt \% Ag$\mathrm{ZnO}$.

addition implies that $\mathrm{Ag}^{+}$ions act as nucleation sites for the $\mathrm{ZnO}$ crystals. ${ }^{29}$ This supports the decrease in crystallite size observed from the XRD and thus the interstitial occupancy of silver ions.

In addition, the lattice spacing was also calculated based on the insets of Figure $2 \mathrm{c}, \mathrm{d}$. For $\mathrm{ZnO}$, the spacing was $0.8 \mathrm{~nm}$, whereas in the case of $\mathrm{Ag}-\mathrm{ZnO}$, it increased to $0.95 \mathrm{~nm}$. This is also evidence for the increase in lattice size upon silver doping. ${ }^{29}$ Hence, the structural and morphological analyses are in good agreement, as the high-resolution TEM (HRTEM) and XRD spectra distinctly correspond to an indexed plane pattern, which confirms the preserved hexagonal wurtzite phase of $\mathrm{ZnO}$, while confirming the expansion of $\mathrm{ZnO}$ crystal lattice and the substitution of $\mathrm{Ag}^{+}$ions.

3.2. Structural and Morphological Analyses of PS/AgZnO Fibers. Structural analysis was done for the polymer and its nanocomposites using the XRD and FTIR tools, and the results obtained are shown in Figure S1, Supporting Information. The small peaks visible during the $30-60^{\circ}$ diffraction angle is because of the (100), (002), (101), (102), and (110) crystal planes of the $\mathrm{ZnO} .{ }^{38}$ These peaks are found to be prominent upon enhancing the $\mathrm{Ag}-\mathrm{ZnO}$ concentration, as indicated in Figure S1a. The broad peaks observed around 10 and $18^{\circ}$ correspond to the PS diffractions. The broadened peaks in the pure PS get narrower as the $\mathrm{ZnO}$ and doped $\mathrm{ZnO}$ concentrations enhance. Moreover, a small peak shift is noted as the concentrations of nanoparticles are increased. This is due to the formation of an additional phase attributed to the nanoparticle distribution and the interphase generated by silver doping at the interstitial sites and $\mathrm{ZnO}$ lattice. ${ }^{39}$ Figure S1b shows the FTIR spectra for all PS nanocomposites. As indicated, the absorption peaks at 3027 and $2923 \mathrm{~cm}^{-1}$ correspond to aromatic $\mathrm{C}-\mathrm{H}$ stretching. The vibrational peaks at 1454,1491 , and $1602 \mathrm{~cm}^{-1}$ are due to the aromatic $\mathrm{C}=\mathrm{C}$ bond stretching in styrene units; however, the intensity change observed is due to the variation in nanoparticle concentration and its influence on the PS bond vibrations. ${ }^{39}$ While the peak at $544 \mathrm{~cm}^{-1}$ corresponds to $\mathrm{Zn}-\mathrm{O}$ bond vibrations, the peak at $695 \mathrm{~cm}^{-1}$ indicates the presence of styrene ring in all of the composites. ${ }^{40}$ The enhancements in peak intensity with filler concentration are indications of PS/ $\mathrm{ZnO}$ or $\mathrm{Ag}-\mathrm{ZnO}$ interactions and the better nanoreinforcements in the composites. ${ }^{41}$

The morphology of the nanofibers was investigated using the SEM images (Figure 3), and the porous nature of the fibers is clearly observed. The pore formation on the surface of all fibers is mainly due to the NIPS mechanism. ${ }^{27}$ When the DMSO fraction in the PS solvent mixture is $7-55 \%$, feasible electrospinning happens due to enhanced conductivity. However, if the PS concentration is low, the polymer chains form discontinuous beads and intermediate concentrations create spindle-like beads. However, at higher PS concentrations (around $30 \mathrm{wt} \%$ ), bead-free fibers are generated. During the synthesis process, the PS undergoes phase separation as the nonsolvent penetrates the polymer structure. As this happens, on the other side, electrospinning evaporates the solvent and decreases the surface temperature. During cooling of the surface, moisture condenses to droplets of water and small imprints are made on the fiber surface. The dimension of the nanocomposite fibers varies from 2.5 to 7.5 $\mu \mathrm{m}$ and the fiber diameter decreases as the nanoparticle concentration enhances. This again confirms the nanoparticle polymer interfacial interaction and influence of $\mathrm{Ag}-\mathrm{ZnO}$ in fiber and pore formation.

The average pore sizes derived from the inset of Figure 3 are $74,95,139,147$, and $176 \mathrm{~nm}$, respectively, for the PS, PS/ $\mathrm{ZnO}, \mathrm{PS} / 1 \mathrm{AgZnO}, \mathrm{PS} / 2 \mathrm{AgZnO}$, and PS/3AgZnO fibers. The pore concentration increases with an increase in the nanoparticle concentration, while the fiber diameter decreases. Considering the nanopores range of $0-100 \mathrm{~nm}$, the composite with $\mathrm{PS} / 3 \mathrm{AgZnO}$ fibers has an average of 40 nanopores, whereas for the plain PS fiber, it is 70 nanopores. Similarly, 

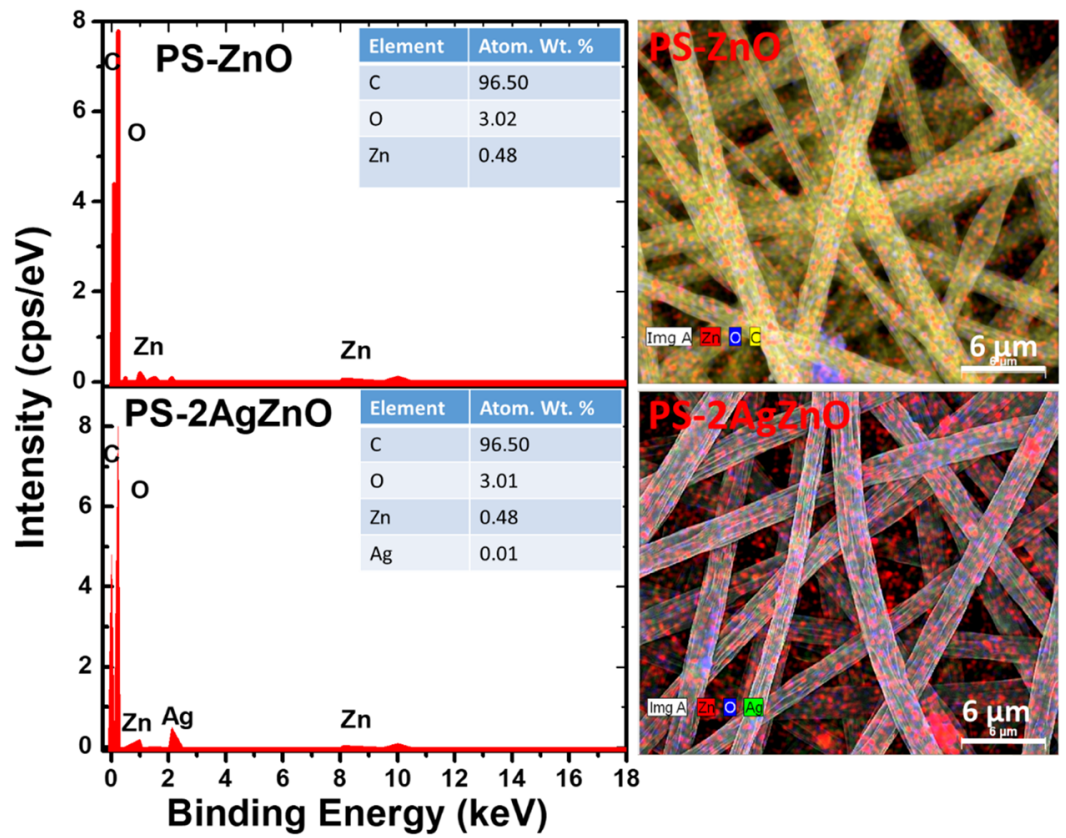

Figure 4. Energy-dispersive spectra and $\mathrm{EDX}$ images for $\mathrm{PS}-\mathrm{ZnO}$ and $\mathrm{PS}-2 \mathrm{AgZnO}$ nanocomposites.

above the $100 \mathrm{~nm}$ range, the average number of nanopores varies from 66 to 27, respectively, for $\mathrm{PS} / 3 \mathrm{AgZnO}$ and PS. Figure S2 (Supporting Information) compares the average pore sizes of the different nanocomposite fibers in the 0-900 $\mathrm{nm}$ range and supports the fact that bigger pores are highly distributed in the fibers of higher nanofiller concentration. This variation in pore size distribution is attributed to the restricted movement of polymer chains due to the presence of nanomaterials and the influence on PS phase separation process.

Figure 4 further shows the dispersion of the nanoparticles within the PS-based nanocomposite. Both PS- $\mathrm{ZnO}$ and PS$2 \mathrm{AgZnO}$ samples were analyzed for the elemental distribution. As evidenced in Figure 4, the corresponding elements $\mathrm{Zn}$ and $\mathrm{Ag}$ are present uniformly in respective samples. The EDS images showed clearly explain the good distribution of the nanoparticles within the nanocomposite. ${ }^{42,43}$ This uniform particle distribution in the PS fibers can influence the fiber porosity as well.

3.3. Mechanical and Thermal Stabilities. Mechanical stability is a very important character for the efficiency of oil separation membranes, as it should withstand a high water flux. Table 1 represents the mechanical strength in terms of Young's modulus, tensile strength, and elongation at break for the PS and its nanocomposites. It is clear from the values that the

Table 1. Mechanical Properties of the PS and Its Nanocomposites Containing $\mathrm{ZnO}$ and $\mathrm{Ag}-\mathrm{ZnO}$

$\begin{array}{lccc}\text { samples } & \begin{array}{c}\text { tensile strength } \\ (\mathrm{MPa})\end{array} & \begin{array}{c}\text { Young's modulus } \\ (\mathrm{MPa})\end{array} & \begin{array}{c}\text { elongation at break } \\ (\%)\end{array} \\ \text { PS } & 1.2 \pm 0.1 & 13.5 \pm 0.3 & 43.0 \pm 2.2 \\ \text { PS-ZnO } & 2.2 \pm 0.6 & 15.6 \pm 0.3 & 40.5 \pm 2.8 \\ \text { PS- } & 1.8 \pm 0.5 & 20.8 \pm 0.4 & 42.5 \pm 0.9 \\ \quad \text { 1AgZnO } & & 36.6 \pm 0.9 & 39.5 \pm 0.5 \\ \text { PS- } & 2.8 \pm 0.2 & & \\ \quad \text { 2AgZnO } & & 34.1 \pm 0.9 & 38.9 \pm 2.5 \\ \text { PS- } & 2.5 \pm 0.5 & & \end{array}$

mechanical properties are enhanced with the addition of nanomaterials. $^{44,45}$ With 2 wt $\% \mathrm{Ag}-\mathrm{ZnO}$, the neat PS increased its Young's modulus by 2.4 times and similar results were observed with the tensile strength as well. However, the nanomaterials do possess a leveling effect after a specific concentration, which is often correlated with the agglomeration issues at higher weight percentages. In our case, the optimum filler concentration is identified as $2 \mathrm{wt} \% \mathrm{Ag}-\mathrm{ZnO}$. Thus, the mechanical stability of the nanocomposite is at its maximum when the filler concentration is 2 wt \%. The elongation at break values also support this concept.

The thermal stabilities of the PS nanocomposites are illustrated in Figure S3. The thermogram and derivative thermogram indicate that the nanoparticles slightly enhance the degradation temperature of PS, which can be attributed to the interaction between the nanoparticles and matrix. While pure PS decomposes at $415.3^{\circ}$, the nanocomposite containing 2 wt $\% \mathrm{Ag}-\mathrm{ZnO}$ decomposes at $419.9^{\circ}$. The inset of the figure marks the onset of degradation temperature, which also shows the higher thermal stability for the composite containing $2 \mathrm{wt}$ $\%$ Ag-ZnO. The Ag-doped $\mathrm{ZnO}$ offers better dispersion and improved the interfacial interaction with PS, compared to $\mathrm{ZnO}$. However, at higher nanoparticle percentages, the possible agglomerations within the polymer medium may overcome and reduce the interaction between the nanoparticles and matrix, negating the increase in thermal stability. This result is in agreement with the findings of $\mathrm{Ma}$ et al., ${ }^{41}$ where they also noted increased thermal stability for the $\mathrm{ZnO}$ composite. $^{42}$

3.4. Oil-Water Separation Strategies. To check the surface hydrophilicity/hydrophobicity, the electrospun fibers are tested for their water contact angle. The values are represented in Figure 5a, in which the hydrophobicity can be clearly observed. As the nanoparticle is added to the PS medium, the contact angle value increased from $122.3^{\circ}$ (pure PS) to a maximum of $136.1^{\circ}$ (PS-3AgZnO). This can be attributed to the improvement in the encapsulation efficiency of the nanomaterials within a polymeric medium. ${ }^{46}$ However, 

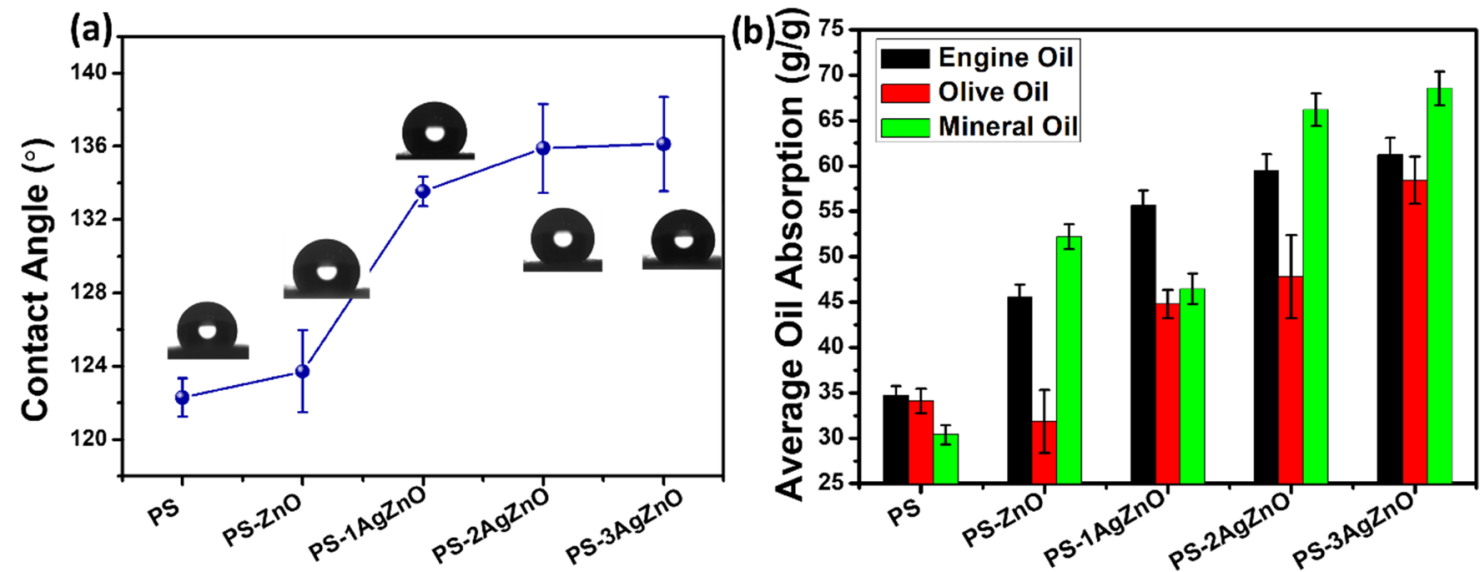

Figure 5. (a) Water contact angles for the PS and PS nanocomposites and (b) average oil adsorption values for all nanocomposites toward various oils.
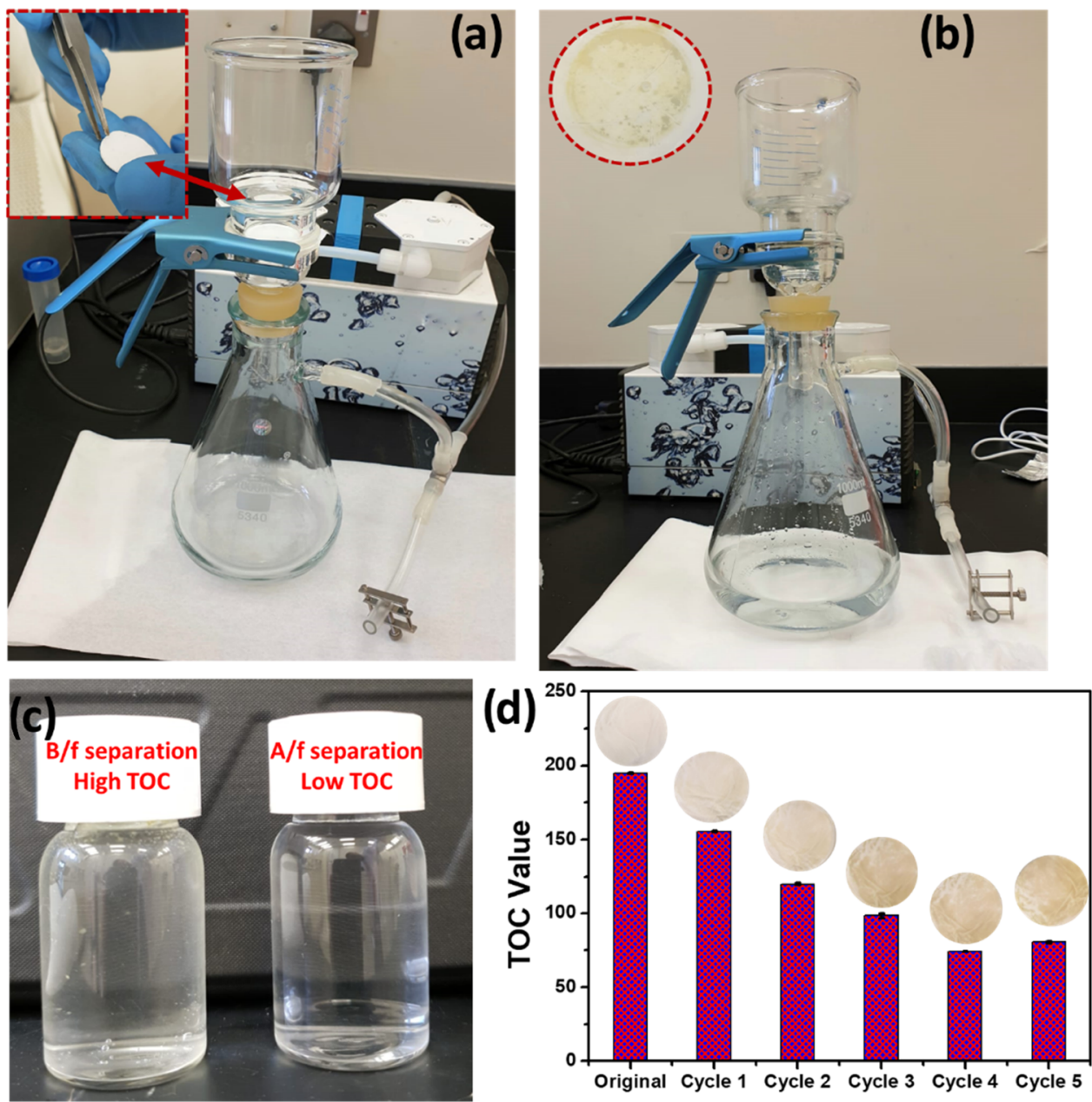

Figure 6. Oil/water separation by the PS-2AgZnO porous fibers: (a) separation setup, (b) oil/water separation, and (c) comparison between the mixture and the separated water. (d) Repeatability of oil separation performance by the fibers for five consecutive cycles. The insets in (a) and (b), respectively, show the fibers before and after separation.

the composite containing 2 wt $\% \mathrm{Ag}-\mathrm{ZnO}$ possesses a contact angle of $135.9^{\circ}$, indicating the leveling effect of the surface hydrophobicity beyond 2 wt \%. This result is in good agreement with the structural and morphological properties of the nanocomposites, which clearly indicated the optimum Ag$\mathrm{ZnO}$ concentration as $2 \mathrm{wt} \%$. Surface porosity induced by the
NIPS process is also responsible for the higher contact angle in addition to the nanoparticle addition.

The oil adsorption capability of the PS nanocomposites was studied using three different oils: engine oil, olive oil, and mineral oil. The average oil adsorption capacities obtained for all samples are illustrated in Figure $5 \mathrm{~b}$. The oil adsorption varies with various parameters such as density and viscosity of 



Figure 7. SEM images of (a) PS and (b) PS-2AgZnO wetted in oil; (c) PS and (d) PS-2AgZO washed with NaOH; and (e) control and (f) PS$2 \mathrm{AgZnO}$ after bacterial growth; the insets show the bacteria-grown samples.

the oil, amount/area of the fiber, immersion time, etc. In this case, the amount of the nanocomposite $(10 \mathrm{mg})$ and adsorption period were kept uniform and the main factors affecting the adsorption performance have been limited to the nature of the nanocomposite and the nature of the oil. In all cases, the oil adsorption property increased with the increase in nanomaterials concentration within the PS polymer. Upon comparing the oils, density and viscosity are the main factors regulating the performance. The density of olive oil $(0.92 \mathrm{~g} /$ $\mathrm{mL})$ was the highest, and that of mineral oil $(0.87 \mathrm{~g} / \mathrm{mL})$ is the least. However, the viscosity values of the oils followed the following trend engine oil $(496 \mathrm{mPa})>$ mineral oil $(154 \mathrm{mPa})$ $>$ olive oil $(68.6 \mathrm{mPa})$. Moreover, the surface tension values of the oils were also measured with respective values of 35,33 , and $32 \mathrm{mN} / \mathrm{m}$ for the olive, engine, and mineral oils. These results point toward the combined influence of density, viscosity, and surface tension of oils on the relative adsorption performance of the fibers. Thus, the polymer nanocomposite can be optimized according to the required adsorption of oil type and the achieved enhancement in the adsorption efficiency. ${ }^{47}$ In addition, the oil adsorption capabilities of the samples were compared with that of a Whatman grade 0858 filter paper of same weight and dimension. The sorption capacities obtained for the filter paper were as follows: $29.5 \mathrm{~g} / \mathrm{g}$ for mineral oil, $29.9 \mathrm{~g} / \mathrm{g}$ for olive oil, and $31.8 \mathrm{~g} / \mathrm{g}$ for engine oil. These values were much lower compared with the results obtained for the PS nanocomposites, which illustrate the ideal 
Table 2. Comparison of Present Data with the Reported Research Works

\begin{tabular}{|c|c|c|c|c|c|}
\hline type of sorbent & structure & type of oil & sorption capacity $(\mathrm{g} / \mathrm{g})$ & reusability & ref \\
\hline \multirow[t]{3}{*}{ clay } & granular & diesel & $5.20-7.20$ & no & 12 \\
\hline & & hydraulic oil & $2.20-3.60$ & & \\
\hline & & engine oil & $2.10-3.60$ & & \\
\hline polypropylene & porous disks & crude oil and petroleum products & $10.10-16$ & 30 cycles & 13 \\
\hline \multirow[t]{2}{*}{ butyl rubber } & macroporous gel & crude oil & $33-38$ & 20 cycles & 14 \\
\hline & & olive oil & $24-27$ & & \\
\hline \multirow[t]{3}{*}{ walnut shell media } & granular & mineral oil & 0.56 & $\mathrm{~N} / \mathrm{A}$ & 15 \\
\hline & & vegetable oil & 0.58 & & \\
\hline & & bright-edge oil & 0.74 & & \\
\hline \multirow{4}{*}{$\begin{array}{l}\text { cotton fiber } \\
\text { current work (PS-2AgZnO) }\end{array}$} & fiber & crude oil tested on water surface and in oil bath. & $30-40$ & 3 cycles & 16 \\
\hline & porous fibers & olive oil & 47.80 & 5 cycles & current work \\
\hline & & mineral oil & 66.18 & & \\
\hline & & engine oil & 59.50 & & \\
\hline
\end{tabular}

application of the proposed porous fiber in cleaning oil contamination.

The oil/water separation efficiencies of the PS nanocomposites were tested using the laboratory setup illustrated in Figure 6 and in Video S1. It is clear from the inset of Figure $6 \mathrm{a}, \mathrm{b}$ that the oil molecules are adsorbed on the fibers. The separated water in Figure $6 \mathrm{c}$ is compared with the preliminary oil/water mixture in terms of total organic content (TOC). It is found that the TOC value for the oil/water emulsion was decreased from $194.7 \pm 0.4$ to $155.5 \pm 0.5$ in separated water, after the first cycle of oil/water separation. This is good evidence for the oil removal efficiency of the porous nanocomposite fibers. The repeatability of oil/water separation is shown in Figure 6d, in the form of five consecutive cycles of separation experiments. It is found that the efficiency of separation increases up to cycle 4; however, at cycle 5, the fiber behaves as saturated with oil.

The durability of the membrane is a prime parameter in industrializing the material application. To test the industrial usage, cleaning and reusing of the fibers were done and the results obtained are compared in Figure 7. The sorption mechanism of the fibers can be clearly observed in Figure $7 a, b$, as the fibrous sample collects oil through a combination of capillary action and adsorption. ${ }^{48,49}$ Adsorption mechanism is demonstrated through the entrapment oil droplets within the empty voids of the fibers, while the capillary action enabled the oil to flow into the porous structure of the prepared polymer nanocomposite. This is represented in Figure $7 \mathrm{a}, \mathrm{b}$ as the pores on the fibers were covered in oil, as they are not visible in the figures. The mechanism of oil adsorption was further verified by the FTIR spectral studies (Figure S4, Supporting Information). As the presence of oil molecules within the fiber structure is identified at $2923 \mathrm{~cm}^{-1}$ absorption frequency, which corresponds to the alkyl $\mathrm{C}-\mathrm{H}$ stretch bonding vibration present in the engine oil. The removal of oil, using $0.1 \mathrm{M}$ $\mathrm{NaOH}$, helps the fibers to get their pores back (Figure $7 \mathrm{c}$ for pure PS, and Figure $7 \mathrm{~d}$ for $\mathrm{PS}-2 \mathrm{AgZnO}$ ); however, comparison with the original SEM images of the fibers in Figure 3 confirms the decreased pore size and fiber flexibility. Chen et al. demonstrated the ability of high-pH cleaning in recovering greater membrane performance in comparison to low-pH cleaning. This is attributed to the alkaline solution ability to dissolve organics, hence being used to remove organic fouling, in comparison to acidic cleaning, which is used to remove inorganic fouling. ${ }^{50,51}$ This general alkali neutralization cleaning process was adopted after each cycle of oil/water separation test. The fibers were tested for five cycles, and the results were consistent.

The sorption capacity and reusability of the PS-2AgZnO sample are compared with the existing sorbents reported in the literature. The comparison is given in Table 2.

Biofouling or formation of hard-to-remove bacterial films on the surface of the material is a serious problem affecting the durability of membranes used for oil-water separation. The antibacterial property of the $\mathrm{PS}-2 \mathrm{AgZnO}$ fibers (Figure $7 \mathrm{f}$ ) is compared against the control (Figure 7e) as indicated. Although neat PS itself has high antibacterial property, ${ }^{52}$ it is further enhanced by the presence of silver-doped $\mathrm{ZnO}$ nanomaterials. $\mathrm{ZnO}$ is notable for its robustness, stability, biosafety, biocompatibility, and nontoxicity, especially in lower concentrations. The particle morphology also affects the antibacterial activity of the $\mathrm{ZnO}$, and they inhibit the growth of many pathogenic bacteria under visible light. Studies reveal that the $\mathrm{ZnO}$ releases reactive oxygen species, mostly hydroxyl radicals, $\mathrm{H}_{2} \mathrm{O}_{2}$, and singlet oxygen, which contribute to their antibacterial activity. In addition, the size of the $\mathrm{ZnO}$ is inversely proportional to the antibacterial influence, as it causes the generation of more reactive oxygen species and also triggers the accumulation of nanoparticles in the cytoplasm or outer membrane of the bacterial cells. ${ }^{53}$ With Ag doping, the antibacterial activity of the nanoparticle further enhances, thus reducing the biofouling.

The bacterial quantification experiment was done in three independent biological replicates. Two-tailed Student's $t$-test was applied on the three data points, and the $P$-value of less than 0.05 was considered statistically significant. As seen in Figure 8 , the bacterial concentration of $S$. aureus was much lower in the polymer nanocomposite sample $\left(3.7 \times 10^{5}\right.$ cells/ $\mathrm{mL})$ in comparison to the control $\left(9.3 \times 10^{5}\right.$ cells $\left./ \mathrm{mL}\right)$. The reason behind the low bacterial concentration of $\mathrm{PS}-2 \mathrm{AgZnO}$ fibers is due to their ability to suppress the migration of the bacteria through the membrane, which is in agreement with SEM imaging found in Figure 7e,f. In addition, the silver nanoparticles have high antibacterial activity, which stems from the free-radical generation by $\mathrm{Ag}$ metals and ions, which are extremely toxic to microorganisms. ${ }^{54,55}$ This substantiates the possibility of the materials use in oil-separating applications as sewage water treatment, produced water treatment, etc.

\section{CONCLUSIONS}

In the current study, we investigated the separation efficiency of oil from laboratory-made oily wastewater (200 ppm oil 


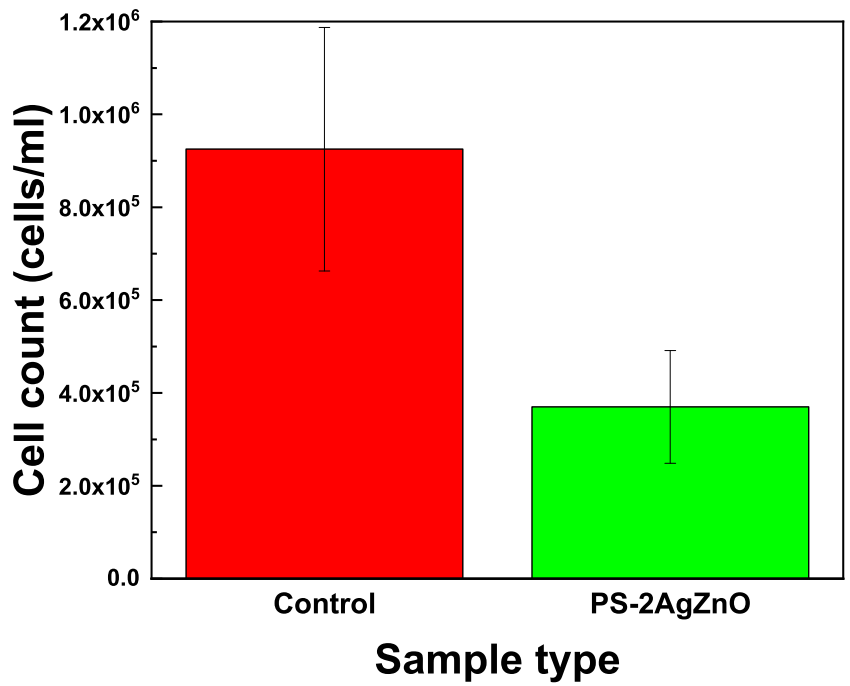

Figure 8. Bacterial cells grown on control filter and PS-2AgZnO were stained with DAPI and counted using a hemocytometer. The counts are presented as mean \pm standard deviation $(\mathrm{SD})(* P<0.05)$.

concentration) using $\mathrm{PS} / \mathrm{Ag}-\mathrm{ZnO}$ nanocomposite porous fibers, with a successful $62 \%$ oil concentration reduction. The major research findings from this study can be summarized as follows: During the nanomaterial synthesis, $\mathrm{Ag}$ ions were doped to the $\mathrm{ZnO}$ lattice with less modification on its structural property, but the amount of silver ions was enough to regulate the significant properties including antibacterial activity. Non-solvent-induced phase separation mechanism was the basic reason to form porous fibers during electrospinning. The surface roughness, pore size, and pore distribution of the fibers were enhanced both by the fabrication method and by the nanoparticle addition, which is quantified through the increase in contact angle from 124 to $136^{\circ}$ and the SEM analysis. Uniformly distributed $\mathrm{Ag}-\mathrm{ZnO}$ nanomaterials make the porous fibers stiff and rough to adsorb a maximum amount of oil, and for mineral oil, the adsorption capacity reached $68.5 \mathrm{~g} / \mathrm{g}$ at the maximum. The durability of the thermally and mechanically stable porous fibers was consistent up to five consecutive levels of the recycling process, and the biofouling was observed to be decreased. All of the experimental results suggest that $\mathrm{Ag} / \mathrm{ZnO}$-modified PS electrospun fibers can be utilized as a promising candidate for oil/water separation

\section{ASSOCIATED CONTENT}

\section{SI Supporting Information}

The Supporting Information is available free of charge at https://pubs.acs.org/doi/10.1021/acsomega.0c05683.

Graphs showing the characterization of PS and its nanocomposites (FTIR spectra, XRD patterns, pore size distribution, thermal degradation behavior, and the oil absorption characteristic) (PDF)

Oil-water separation experiments by the porous composite fiber (MP4)

\section{AUTHOR INFORMATION}

\section{Corresponding Authors}

Mohammad K. Hassan - Center for Advanced Materials, Qatar University, Doha, Qatar; Phone: +974) 4403 5660; Email: mohamed.hassan@qu.edu.qa
Alamgir Karim - Department of Chemical and Biomolecular Engineering, University of Houston, Houston, Texas 77204, United States; 이이.org/0000-0003-1302-9374; Phone: +1) 713-743-7351; Email: akarim3@ Central.UH.EDU

\section{Authors}

Ali A. El-Samak - Center for Advanced Materials, Qatar University, Doha, Qatar

Deepalekshmi Ponnamma - Center for Advanced Materials, Qatar University, Doha, Qatar

Samer Adham - ConocoPhilips Global Water Sustainability Center, Qatar Science and Technology Park, Doha, Qatar; (1) orcid.org/0000-0003-1245-2453

Ali Ammar - Department of Chemical and Biomolecular Engineering, University of Houston, Houston, Texas 77204, United States

Maha Alser - Biomedical Research Center, Qatar University, Doha, Qatar

Samar Shurbaji - Biomedical Research Center, Qatar University, Doha, Qatar

Nahla O. Eltai - Biomedical Research Center, Qatar University, Doha, Qatar

Mariam Al Ali Al-Maadeed - Materials Science and Technology Program, Qatar University, Doha, Qatar

Complete contact information is available at:

https://pubs.acs.org/10.1021/acsomega.0c05683

\section{Author Contributions}

A.A.E. preformed the experiments. A.A.E. and D.P. drafted the manuscript and designed the figures. M.K.H. and M.A. supervised the project and contributed to data analysis. M.A., S.S., and N.O.E. contributed to biological testing and data analysis. S.A., A.K., and A.A. provided guidance and insight for the structural analysis and oil/water separation tests. All authors have given approval to the final version of the manuscript.

\section{Funding}

This publication was made possible by NPRP grant 10-0127170269 from the Qatar National Research Fund (a member of Qatar Foundation). The statements made herein are solely the responsibility of the authors. The SEM, TEM, and EDS analyses were accomplished in the Central Laboratories Unit, Qatar University. A.A.E. acknowledges Qatar University for the support granted through Graduate Research Assistantship Program (GRA).

Notes

The authors declare no competing financial interest.

\section{REFERENCES}

(1) Janson, A.; Minier-Matar, J.; Al-Shamari, E.; Hussain, A.; Sharma, R.; Rowley, D.; Adham, S. Evaluation of new ion exchange resins for hardness removal from boiler feedwater. Emergent Mater. 2018, 1, 77-87.

(2) Nagaraj, A.; Govindaraj, D.; Rajan, M. Magnesium oxide entrapped Polypyrrole hybrid nanocomposite as an efficient selective scavenger for fluoride ion in drinking water. Emergent Mater. 2018, 1, 25-33.

(3) Abdullah, N.; Yusof, N.; Ismail, A. F.; Othman, F. E. C.; Jaafar, J.; Jye, L. W.; Salleh, W. N. W.; Aziz, F.; Misdan, N. Effects of manganese (VI) oxide on polyacrylonitrile-based activated carbon nanofibers (ACNFs) and its preliminary study for adsorption of lead (II) ions. Emergent Mater. 2018, 1, 89-94. 
(4) Elgawady, Y.; Ponnamma, D.; Adham, S.; Al-Maas, M.; Ammar, A.; Alamgir, K.; Al-Maadeed, M. A.; Hassan, M. K. Mesoporous silica filled smart super oleophilic fibers of triblock copolymer nanocomposites for oil absorption applications. Emergent Mater. 2020, 3, 279-290.

(5) Li, J.-J.; Zhou, Y.-N.; Luo, Z.-H. Polymeric materials with switchable superwettability for controllable oil/water separation: A comprehensive review. Prog. Polym. Sci. 2018, 87, 1-33.

(6) Guan, Y.; Cheng, F.; Pan, Z. Superwetting polymeric three dimensional (3d) porous materials for oil/water separation: A review. Polymers 2019, 11, No. 806.

(7) Laad, M.; Ponnamma, D.; Sadasivuni, K. K. Tribological studies of nanomodified mineral based multi-grade engine oil. Int. J. Appl. Eng. Res. 2017, 12, 2855-2861.

(8) Li, A.; Sun, H.-X.; Tan, D.-Z.; Fan, W.-J.; Wen, S.-H.; Qing, X.-J.; Li, G.-X.; Li, S.-Y.; Deng, W.-Q. Superhydrophobic conjugated microporous polymers for separation and adsorption. Energy Environ. Sci. 2011, 4, 2062-2065.

(9) Zhang, J.; Seeger, S. Polyester materials with superwetting silicone nanofilaments for oil/water separation and selective oil absorption. Adv. Funct. Mater. 2011, 21, 4699-4704.

(10) Wu, L.; Zhang, J.; Li, B.; Wang, A. Mechanical-and oil-durable superhydrophobic polyester materials for selective oil absorption and oil/water separation. J. Colloid Interface Sci. 2014, 413, 112-117.

(11) Chen, N.; Pan, Q. Versatile fabrication of ultralight magnetic foams and application for oil-water separation. ACS Nano 2013, 7, $6875-6883$.

(12) Carmody, O.; Frost, R.; Xi, Y.; Kokot, S. Adsorption of hydrocarbons on organo-clays-implications for oil spill remediation. J. Colloid Interface Sci. 2007, 305, 17-24.

(13) Ceylan, D.; Dogu, S.; Karacik, B.; Yakan, S. D.; Okay, O. S.; Okay, O. Evaluation of butyl rubber as sorbent material for the removal of oil and polycyclic aromatic hydrocarbons from seawater. Environ. Sci. Technol. 2009, 43, 3846-3852.

(14) Karakutuk, I.; Okay, O. Macroporous rubber gels as reusable sorbents for the removal of oil from surface waters. React. Funct. Polym. 2010, 70, 585-595.

(15) Srinivasan, A.; Viraraghavan, T. Removal of oil by walnut shell media. Boresour. Technol. 2008, 99, 8217-8220.

(16) Al-Majed, A. A.; Adebayo, A. R.; Hossain, M. E. A sustainable approach to controlling oil spills. J. Environ. Manage. 2012, 113, 213227.

(17) Parangusan, H.; Ponnamma, D.; Al-Maadeed, M. A. A. Stretchable electrospun PVDF-HFP/Co- $\mathrm{ZnO}$ nanofibers as piezoelectric nanogenerators. Sci. Rep. 2018, 8, No. 754.

(18) Issa, A. A.; Al-Maadeed, M. A.; Luyt, A. S.; Ponnamma, D.; Hassan, M. K. Physico-mechanical, dielectric, and piezoelectric properties of PVDF electrospun mats containing silver nanoparticles. C 2017, 3, No. 30

(19) Ma, W.; Zhang, Q.; Hua, D.; Xiong, R.; Zhao, J.; Rao, W.; Huang, S.; Zhan, X.; Chen, F.; Huang, C. Electrospun fibers for oilwater separation. RSC Adv. 2016, 6, 12868-12884.

(20) Zhai, T.-L.; Du, Q.; Xu, S.; Wang, Y.; Zhang, C. Electrospun nanofibrous membrane of porous fluorine-containing triptycene-based polyimides for oil/water separation. RSC Adv. 2017, 7, 22548-22552.

(21) Zhao, J.; Wang, W.; Ye, C.; Li, Y.; You, J. Gravity-driven ultrafast separation of water-in-oil emulsion by hierarchically porous electrospun poly(L-lactide) fabrics. J. Membr. Sci. 2018, 563, 762767.

(22) Panatdasirisuk, W.; Liao, Z.; Vongsetskul, T.; Yang, S. Separation of oil-in-water emulsions using hydrophilic electrospun membranes with anisotropic pores. Langmuir 2017, 33, 5872-5878.

(23) El-Samak, A. A.; Ponnamma, D.; Hassan, M. K.; Ammar, A.; Adham, S.; Al-Maadeed, M. A. A.; Karim, A. Designing Flexible and Porous Fibrous Membranes for Oil Water Separation-A Review of Recent Developments. Polym. Rev. 2020, 671-716.

(24) Anitha, S.; Brabu, B.; Thiruvadigal, D. J.; Gopalakrishnan, C.; Natarajan, T. Optical, bactericidal and water repellent properties of electrospun nano-composite membranes of cellulose acetate and ZnO. Carbohydr. Polym. 2012, 87, 1065-1072.

(25) Singh, P.; Mondal, K.; Sharma, A. Reusable electrospun mesoporous $\mathrm{ZnO}$ nanofiber mats for photocatalytic degradation of polycyclic aromatic hydrocarbon dyes in wastewater. J. Colloid Interface Sci. 2013, 394, 208-215.

(26) Patel, S.; Konar, M.; Sahoo, H.; Hota, G. Surface functionalization of electrospun PAN nanofibers with $\mathrm{ZnO}-\mathrm{Ag}$ heterostructure nanoparticles: synthesis and antibacterial study. Nanotechnology 2019, 30, No. 205704.

(27) Wu, J.; Wang, N.; Wang, L.; Dong, H.; Zhao, Y.; Jiang, L. Electrospun porous structure fibrous film with high oil adsorption capacity. ACS Appl. Mater. Interfaces 2012, 4, 3207-3212.

(28) Chen, P.-Y.; Tung, S.-H. One-step electrospinning to produce nonsolvent-induced macroporous fibers with ultrahigh oil adsorption capability. Macromolecules 2017, 50, 2528-2534.

(29) Yıldırım, Ö. A.; Unalan, H. E.; Durucan, C. Highly efficient room temperature synthesis of silver-doped zinc oxide ( $\mathrm{ZnO}: \mathrm{Ag}$ ) nanoparticles: structural, optical, and photocatalytic properties. J. Am. Ceram. Soc. 2013, 96, 766-773.

(30) Ravishankar, T.; Manjunatha, K.; Ramakrishnappa, T.; Nagaraju, G.; Kumar, D.; Sarakar, S.; Anandakumar, B.; Chandrappa, G.; Reddy, V.; Dupont, J. Comparison of the photocatalytic degradation of trypan blue by undoped and silverdoped zinc oxide nanoparticles. Mater. Sci. Semicond. Process. 2014, 26, 7-17.

(31) Sabri, S.; Najjar, A.; Manawi, Y.; Eltai, N. O.; Al-Thani, A.; Atieh, M. A.; Kochkodan, V. Antibacterial Properties of Polysulfone Membranes Blended with Arabic Gum. Membranes 2019, 9, No. 29.

(32) Georgekutty, R.; Seery, M. K.; Pillai, S. C. A highly efficient Ag$\mathrm{ZnO}$ photocatalyst: synthesis, properties, and mechanism. J. Phys. Chem. C 2008, 112, 13563-13570.

(33) Hosseini, S.; Sarsari, I. A.; Kameli, P.; Salamati, H. Effect of Ag doping on structural, optical, and photocatalytic properties of $\mathrm{ZnO}$ nanoparticles. J. Alloys Compd. 2015, 640, 408-415.

(34) Ibrahim, A. A.; Dar, G.; Zaidi, S. A.; Umar, A.; Abaker, M.; Bouzid, H.; Baskoutas, S. Growth and properties of Ag-doped $\mathrm{ZnO}$ nanoflowers for highly sensitive phenyl hydrazine chemical sensor application. Talanta 2012, 93, 257-263.

(35) Khosravi-Gandomani, S.; Yousefi, R.; Jamali-Sheini, F.; Huang, N. M. Optical and electrical properties of p-type Ag-doped $\mathrm{ZnO}$ nanostructures. Ceram. Int. 2014, 40, 7957-7963.

(36) Parangusan, H.; Ponnamma, D.; Al-Maadeed, M. A. A. Effect of cerium doping on the optical and photocatalytic properties of $\mathrm{ZnO}$ nanoflowers. Bull. Mater. Sci. 2019, 42, No. 179.

(37) Parangusan, H.; Ponnamma, D.; Al-Maadeed, M. A. A.; Marimuthu, A. Nanoflower-like yttrium-doped $\mathrm{ZnO}$ photocatalyst for the degradation of methylene blue dye. Photochem. Photobiol. 2018, 94, 237-246.

(38) Zang, Z.; Wen, M.; Chen, W.; Zeng, Y.; Zu, Z.; Zeng, X.; Tang, $\mathrm{X}$. Strong yellow emission of $\mathrm{ZnO}$ hollow nanospheres fabricated using polystyrene spheres as templates. Mater. Des. 2015, 84, 418421.

(39) Jeeju, P.; Jayalekshmi, S. On the interesting optical properties of highly transparent, thermally stable, spin-coated polystyrene/zinc oxide nanocomposite films. J. Appl. Polym. Sci. 2011, 120, 1361-1366.

(40) Chae, D. W.; Kim, B. C. Characterization on polystyrene/zinc oxide nanocomposites prepared from solution mixing. Polym. Adv. Technol. 2005, 16, 846-850.

(41) Ma, C. C. M.; Chen, Y. J.; Kuan, H. C. Polystyrene nanocomposite materials-preparation, mechanical, electrical and thermal properties, and morphology. J. Adv. Polym. Sci. 2006, 100, $508-515$.

(42) Wei, W.; Zhang, Y.; Liu, M.; Zhang, Y.; Yin, Y.; Gutowski, W. S.; Deng, P.; Zheng, C. Improving the Damping Properties of Nanocomposites by Monodispersed Hybrid POSS Nanoparticles: Preparation and Mechanisms. Polymers 2019, 11, No. 647. 
(43) Mansour, S. A. Study of thermal stabilization for polystyrene/ carbon nanocomposites via TG/DSC techniques. J. Therm. Anal. Calorim. 2013, 112, 579-583.

(44) Ponnamma, D.; Ramachandran, R.; Hussain, S.; Rajaraman, R.; Amarendra, G.; Varughese, K.; Thomas, S. Free-volume correlation with mechanical and dielectric properties of natural rubber/multi walled carbon nanotubes composites. Composites, Part A 2015, 77, $164-171$.

(45) Devi, K. S. U.; Ponnamma, D.; Causin, V.; Maria, H. J.; Thomas, S. Enhanced morphology and mechanical characteristics of clay/styrene butadiene rubber nanocomposites. Appl. Clay Sci. 2015, $114,568-576$.

(46) Tang, E.; Dong, S. Preparation of styrene polymer/ZnO nanocomposite latex via miniemulsion polymerization and its antibacterial property. Colloid Polym. Sci. 2009, 287, 1025-1032.

(47) Duong, H. T.; Burford, R. P. Effect of foam density, oil viscosity, and temperature on oil sorption behavior of polyurethane. J. Appl. Polym. Sci. 2006, 99, 360-367.

(48) Lin, J.; Shang, Y.; Ding, B.; Yang, J.; Yu, J.; Al-Deyab, S. S. Nanoporous polystyrene fibers for oil spill cleanup. Mar. Pollut. Bull. 2012, 64, 347-352.

(49) Wu, J.; An, A. K.; Guo, J.; Lee, E.-J.; Farid, M. U.; Jeong, S. CNTs reinforced super-hydrophobic-oleophilic electrospun polystyrene oil sorbent for enhanced sorption capacity and reusability. Chem. Eng. J. 2017, 314, 526-536.

(50) Chen, J. P.; Kim, S.; Ting, Y. Optimization of membrane physical and chemical cleaning by a statistically designed approach. J. Membr. Sci. 2003, 219, 27-45.

(51) Li, X.; Cai, T.; Amy, G. L.; Chung, T.-S. Cleaning strategies and membrane flux recovery on anti-fouling membranes for pressure retarded osmosis. J. Membr. Sci. 2017, 522, 116-123.

(52) Youssef, A. M.; Kamel, S.; El-Samahy, M. Morphological and antibacterial properties of modified paper by PS nanocomposites for packaging applications. Carbohydr. Polym. 2013, 98, 1166-1172.

(53) Raghupathi, K. R.; Koodali, R. T.; Manna, A. C. Size-dependent bacterial growth inhibition and mechanism of antibacterial activity of zinc oxide nanoparticles. Langmuir 2011, 27, 4020-4028.

(54) Rastogi, S. K.; Rutledge, V. J.; Gibson, C.; Newcombe, D. A.; Branen, J. R.; Branen, A. L. Ag colloids and Ag clusters over EDAPTMS-coated silica nanoparticles: synthesis, characterization, and antibacterial activity against Escherichia coli. Nanomedicine 2011, $7,305-314$

(55) Salomoni, R.; Léo, P.; Montemor, A.; Rinaldi, B.; Rodrigues, M. Antibacterial effect of silver nanoparticles in Pseudomonas aeruginosa. Nanotechnol., Sci. Appl. 2017, 10, 115. 